\title{
Rapunzel syndrome
}

\author{
Ahmed Youssef Altonbary, Monir Hussein Bahgat \\ Department of Hepatology and Gastroenterology, Mansoura Specialized Medical Hospital, Mansoura, Egypt
}

\section{ABSTRACT}

Bezoars are concretions of human or vegetable fibers that accumulate in the gastrointestinal tract. Trichobezoars are common in patients with underlying psychiatric disorders who chew and swallow their own hair. Rapunzel syndrome is a rare form of gastric trichobezoar with a long tail extending into the small bowel. This syndrome was first described in 1968 by Vaughan et al. and since then till date just 64 cases have been described in the literature. We present the only documented case with Rapunzel syndrome in Egypt.

Key words: Rapunzel syndrome, trichobezoar, trichophagia, trichotillomania

\section{INTRODUCTION}

Bezoars are concretions of human or vegetable fibers that accumulate in the gastrointestinal tract. The word "bezoar" comes from the Arabic word "bedzehr" or the Persian word "padzhar," meaning "protecting against a poison." At different times in history, bezoars from animal guts were used as antidotes to poisons and today as part of traditional Chinese medicine. ${ }^{[1]}$ The first reference to a bezoar in a human was in 1779 during an autopsy of a patient who died from gastric perforation and peritonitis. ${ }^{[2,3]}$ The following four types of bezoars have been described: phytobezoars (comprising vegetable or fruit fibers), lactobezoars (comprising milk curds), trichobezoars (comprising hair) and pharmacobezoars (comprising pills or capsules) $\cdot^{[4]}$ Unlike other bezoars, trichobezoars are common in patients with underlying psychiatric disorders who chew and swallow their own hair (i.e., trichotillomania and/or trichophagia). Rapunzel syndrome is a rare form of gastric trichobezoar with a long tail extending into the small bowel..$^{[5]}$ The term comes from a story written by the Grimm brothers in 1812 about Rapunzel, who was a longhaired maiden. She lowered her tresses to allow her prince to climb up to her prison tower to rescue her. ${ }^{[2]}$ This syndrome was first described in 1968 by Vaughan et al. ${ }^{[3]}$ and since then till date just 64 cases have been described in the literature. ${ }^{[6]}$ We present the only documented case with Rapunzel syndrome in Egypt.

\section{CASE REPORT}

A 15-year-old female had presented with the complaints of intermittent abdominal pain, nausea, vomiting, and early satiety. Five months back, her parents had noticed that she has the habit of picking and eating hair from her head. History of irritable behavior was present. On examination, there was a movable, nontender, firm epigastric mass of $8 \mathrm{~cm} \times 3 \mathrm{~cm}$ in size. Contrast-enhanced computed tomography (CT) abdomen revealed a large, well-circumscribed, nonhomogeneous lesion in the lumen of the stomach that was composed of concentric whorls of different densities that had pockets of air enmeshed within it. This was suggestive of trichobezoar. Removal attempt through an upper gastrointestinal endoscopy was considered. Upper gastroscopy revealed a huge gastric trichobezoar mixed with undigested food material occupying almost the entire gastric cavity [Figure 1]. A long hairy tail was exiting the pylorus and extending into the duodenum [Figure 2]; the gastric mucosa appeared normal without evidence of ulceration. An attempt to remove the trichobezoar using foreign body forceps failed because of its extensive size. Consequently, surgical laparotomy was 


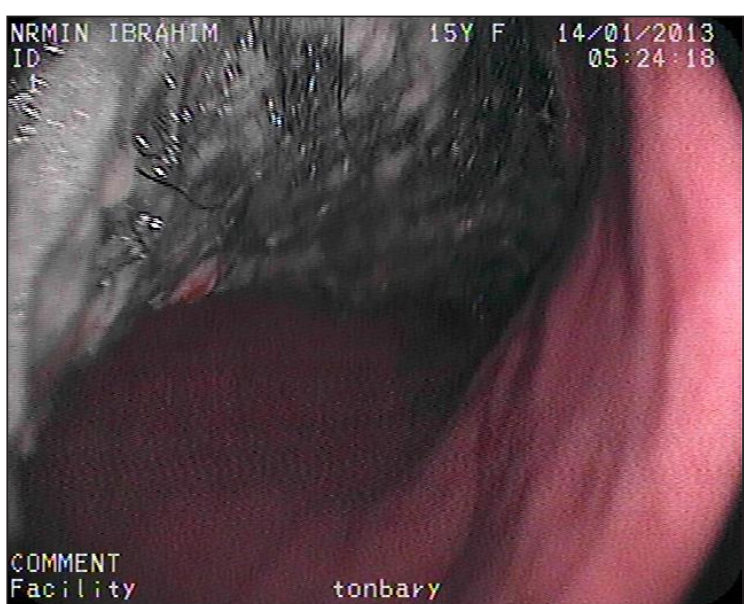

Figure 1: Huge gastric trichobezoar mixed with undigested food material occupying almost the entire gastric cavity

performed. During laparotomy, a mass was palpated in the stomach, which was removed by gastrostomy. The mass consisted of hair and mixed with undigested food material that occupied the entire length of the gastric chamber and extending through the duodenum up to $5 \mathrm{~cm}$ of jejunum. Trichotillomania was diagnosed on psychiatric assessment and treated accordingly. Now she is maintaining well.

\section{DISCUSSION}

Bezoars are concretions of foreign material in the gastrointestinal tract, mainly the stomach. Bezoars composed of hair or hair-like fibers are called trichobezoars. Most patients with trichobezoars suffer from psychiatric disorders including trichotillomania (pulling out of their own hair) and trichophagia (eating of hair). Only rarely do these patients chew hair from other sources including hair from wigs. It has been estimated that only $1 \%$ of patients with trichophagia develop a trichobezoar. ${ }^{[7,8]}$ Trichobezoars form when hair strands, escaping peristaltic propulsion because of their slippery surface, are retained in the folds of the gastric mucosa. As more hair accumulates, peristalsis causes it to be enmeshed into a ball. The ball of hair becomes even more matted together and assumes the shape of the stomach, usually as a single solid mass. ${ }^{[9,10]}$ When trichobezoar extends from the stomach into the duodenum, the proximal small intestine or to the ascending colon, it is called Rapunzel syndrome. The syndrome was first described in 1968 by Vaughan et al. and since then till date just 64 cases have been described in the literature [Table 1]. ${ }^{[6]}$ Trichobezoars are most commonly seen in females (approximately 90\%) aged between 10 and 19 years but only in half of these patients is a history of trichophagia found. ${ }^{[11]}$ Trichobezoars are usually symptomless until they reach a large size. They may present with varied upper gastrointestinal

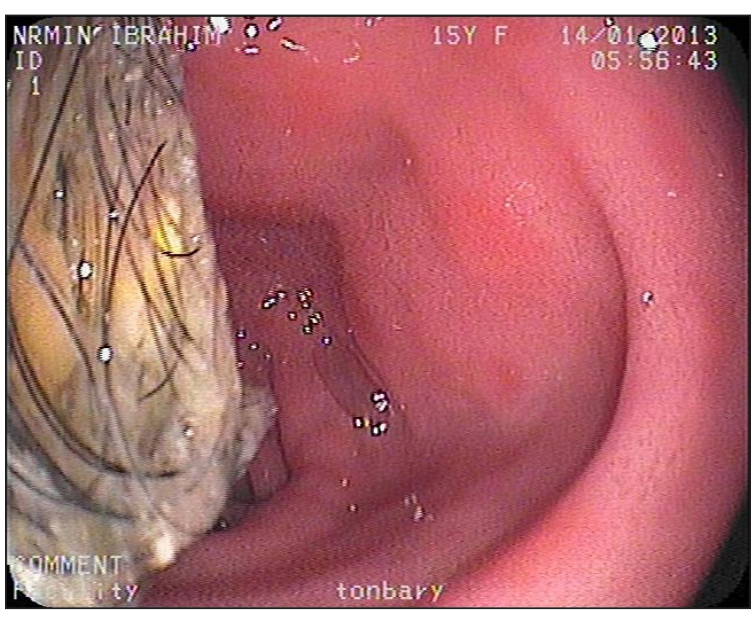

Figure 2: A long hairy tail extending into the duodenum

Table 1: Brief review of Rapunzel syndrome

\begin{tabular}{|c|c|}
\hline Article(s) & Special features \\
\hline Rabie et al. ${ }^{[5]}$ & $\begin{array}{l}\text { Reported that only } 24 \text { cases have been } \\
\text { reported in the literature. One of them was } \\
\text { pregnant and had small bowel intussusception } \\
\text { and perforation, a very rare combination }\end{array}$ \\
\hline Mohite et al. ${ }^{[19]}$ & $\begin{array}{l}\text { Case report of on table diagnosis } \\
\text { of Rapunzel syndrome in a case operated } \\
\text { for gastric perforation. They review } \\
27 \text { cases of Rapunzel syndrome }\end{array}$ \\
\hline Dindyal et al. ${ }^{[20]}$ & $\begin{array}{l}\text { Case report describing unusual radiologic } \\
\text { sign associated with a retroperitoneal } \\
\text { perforation of the third part of } \\
\text { duodenum - the comma sign }\end{array}$ \\
\hline Salem et al. ${ }^{[21]}$ & $\begin{array}{l}\text { Case report of Rapunzel syndrome that } \\
\text { was complicated by pancreatitis }\end{array}$ \\
\hline Mateju et al..$^{[22]}$ & $\begin{array}{l}\text { Reported death resulting from Rapunzel } \\
\text { syndrome due to gastric perforation and } \\
\text { parental neglect }\end{array}$ \\
\hline Jones et al. ${ }^{[23]}$ & $\begin{array}{l}\text { Recurrent Rapunzel syndrome in a } \\
\text { 37-year-old woman }\end{array}$ \\
\hline Jain et al. ${ }^{[24]}$ & $\begin{array}{l}\text { Case report of a large trichobezoar in a } \\
\text { 3-year-old male child who presented to } \\
\text { the emergency department with threads } \\
\text { protruding from mouth with no sign of hair } \\
\text { loss on body }\end{array}$ \\
\hline 28 simple cases & No special feature described \\
\hline
\end{tabular}

symptoms, wasting and cachexia. Large bezoars are often palpable and may be indentable (Lamerton's sign). The main complications of trichobezoar include ulceration, gastrointestinal perforation, obstruction, intussusception, diarrhea and vitamin B12 deficiency (secondary to bacterial overgrowth by colonization of the bezoar). ${ }^{[6]}$ Elucidating a patient's history of trichotillomania and/ or trichophagia is essential for the diagnosis of Rapunzel syndrome or trichobezoars. In some patients, putrid halitosis and patchy alopecia can be clues on physical examination. Imaging studies including plain abdominal radiograph, contrast upper gastrointestinal series, and abdominal CT scan may show the trichobezoar as a mass or filling defect in the stomach and small bowel. ${ }^{[12]}$ 
The gold standard for diagnosis is upper gastrointestinal endoscopy. In addition to providing direct visualization, this procedure allows sample taking and potentially therapeutic intervention. ${ }^{[4]}$ The management of a bezoar needs to encompass removal of the mass and prevention of recurrence by addressing the underlying physical or emotional cause. Depending on its consistency, size, and location, bezoar removal may occur via endoscopy or surgery. Endoscopic therapy can be effective for bezoars composed of vegetable matter (phytobezoars) and milk curd (lactobezoars), as they are small in size, but is less likely to be effective for trichobezoars, particularly those that are large $(>20 \mathrm{~cm}) \cdot{ }^{[4]}$ Specialized bezotomes and bezotriptors (medical devices that pulverize bezoars either mechanically or with acoustic waves) have been used to fragment large and solid trichobezoars. ${ }^{[13]}$ Surgery is indicated when a very large or solid bezoar causes perforation or hemorrhage, or in the case of Rapunzel syndrome, when there is a significant extension of the bezoar. ${ }^{[7]}$ Surgical removal is accomplished by gastrotomy or enterotomy. Traditionally, a gastric trichobezoar was removed by the gastrotomy through an upper midline laparotomy. Since the advent of minimally invasive surgery, surgeons now use laparoscopic techniques for small to moderate size bezoars. ${ }^{[14,15]}$ Various other methods like extracorporeal shock wave lithotripsy, intragastric administration of enzymes (pancreatic lipase, cellulose), and medications (metoclopramide, acetylcysteine) demonstrate varying success. ${ }^{[14]} \mathrm{Few}$ recurrences are reported after the initial removal of bezoars. ${ }^{[15,16]}$ To decrease recurrence, longterm psychiatric follow-up is advised. Although data on treatment efficacy is inconclusive, common modalities include cognitive behavior therapy and pharmacological treatment. ${ }^{[17]}$ Several pharmacological modalities have been used corresponding to distinct views on the etiology of trichotillomania, including impulse-control disorders, obsessive-compulsive disorders, behavioral problems, and addiction. ${ }^{[18]}$

\section{CONCLUSION}

Rapunzel syndrome is a rare entity which is underdiagnosed. In young girls with psychiatric history, who present with abdominal pain, vomiting or abdominal mass, bezoars/Rapunzel syndrome should be considered in the differential diagnosis.

\section{REFERENCES}

1. Wang C, Zhao X, Mao S, Wang Y, Cui X, Pu Y. Management of SAH with traditional Chinese medicine in China. Neurol Res 2006;28:436-44.

2. Naik S, Gupta V, Naik S, Rangole A, Chaudhary AK, Jain P, et al. Rapunzel syndrome reviewed and redefined. Dig Surg 2007;24:157-61.

3. Vaughan ED Jr, Sawyers JL, Scott HW Jr. The Rapunzel syndrome. An unusual complication of intestinal bezoar. Surgery 1968;63:339-43.

4. Gonuguntla V, Joshi DD. Rapunzel syndrome: A comprehensive review of an unusual case of trichobezoar. Clin Med Res 2009;7:99-102.

5. Rabie ME, Arishi AR, Khan A, Ageely H, Seif El-Nasr GA, Fagihi M. Rapunzel syndrome: The unsuspected culprit. World J Gastroenterol 2008;14:1141-3.

6. Sharma AK, Hussain A, Walia D, Bansal S. Trichobezoar and Rapunzel syndrome: A review. Oncol Gastroenterol Hepatol Rep 2015;4:28-9.

7. Phillips MR, Zaheer S, Drugas GT. Gastric trichobezoar: Case report and literature review. Mayo Clin Proc 1998;73:653-6.

8. Irving PM, Kadirkamanathan SS, Priston AV, Blanshard C. Education and imaging. Gastrointestinal: Rapunzel syndrome. J Gastroenterol Hepatol 2007;22:2361.

9. Pace AP, Fearne C. Trichobezoar in a 13 year old male: A case report and review of literature. Malta Med J 2003;15:39-40.

10. Deslypere JP, Praet M, Verdonk G. An unusual case of the trichobezoar: The Rapunzel syndrome. Am J Gastroenterol 1982;77:467-70.

11. Dogra S, Kulkarni AK, Rao PP. Rapunzel syndrome-A case report. Med J Armed Forces India 2012;68:249-51.

12. West WM, Duncan ND. CT appearances of the Rapunzel syndrome: An unusual form of bezoar and gastrointestinal obstruction. Pediatr Radiol 1998;28:315-6.

13. Wang YG, Seitz U, Li ZL, Soehendra N, Qiao XA. Endoscopic management of huge bezoars. Endoscopy 1998;30:371-4.

14. Groenewald CB, Smoot RL, Farley DR. A football-sized gastric mass in a healthy teen. Contemp Surg 2006;62:531-4.

15. Eryilmaz R, Sahin M, Alimoglu O, Yildiz MK. A case of Rapunzel syndrome. Ulus Travma Acil Cerrahi Derg 2004;10:260-3.

16. Memon SA, Mandhan P, Qureshi JN, Shairani AJ. Recurrent Rapunzel syndrome - A case report. Med Sci Monit 2003;9:CS92-4.

17. Christenson GA, Crow SJ. The characterization and treatment of trichotillomania. J Clin Psychiatry 1996;57 Suppl 8:42-7.

18. Shoenfeld N, Rosenberg O, Kotler M, Dannon PN. Tricotillomania: Pathopsychology theories and treatment possibilities. Isr Med Assoc J 2012;14:125-9.

19. Mohite PN, Gohil AB, Wala HB, Vaza MA. Rapunzel syndrome complicated with gastric perforation diagnosed on operation table. J Gastrointest Surg 2008;12:2240-2.

20. Dindyal S, Bhuva Nj, Dindyal S, Ramdass M, Narayansingh V. Trichobezoar presenting with the 'comma sign' in Rapunzel Syndrome: A case report and literature review. Cases J 2008;1:286.

21. Salem M, Fouda R, Fouda U, Maadawy ME, Ammar H. Rapunzel and pregnancy. South Med J 2009;102:106-7.

22. Mateju E, Duchanová S, Kovac P, Moravanský N, Spitz DJ. Fatal case of Rapunzel syndrome in neglected child. Forensic Sci Int 2009;190:e5-7.

23. Jones GC, Coutinho K, Anjaria D, Hussain N, Dholakia R. Treatment of recurrent Rapunzel syndrome and trichotillomania: Case report and literature review. Psychosomatics 2010;51:443-6.

24. Jain M, Solanki SL, Bhatnagar A, Jain PK. An unusual case report of rapunzel syndrome trichobezoar in a 3-year-old boy. Int J Trichology 2011;3:102-4.

How to cite this article: Altonbary AY, Bahgat $\mathrm{MH}$. Rapunzel syndrome. J Transl Intern Med 2015;3:79-81

Source of Support: NIL, Conflict of Interest: NIL 